\title{
Characteristics of the Amino
}

\section{Acid Transport System in the \\ Mucosal Border of Rabbit Ileum}

\author{
JEAN JACQUES HAJJAR and PETER F. CURRAN \\ From the Department of Physiology, Yale University School of Medicine, New Haven, \\ Connecticut 06510
}

\begin{abstract}
The specificity of the neutral amino acid transport system in the brush border was examined by studying the ability of amino acid analogues to inhibit the unidirectional influx of phenylalanine from mucosal solution into the cells. Effects were evaluated in terms of the affinity of various substrates for the amino acid site in the transport system. The affinity of amino acids for the site was proportional to the number of carbon atoms in the side chain. Electronwithdrawing substituents in the ring of phenylalanine increased affinity and electron-releasing groups decreased affinity. Removal of the $\alpha$-amino group from phenylalanine decreased affinity by a factor of approximately 50 and removal of the carboxyl group decreased affinity 12-fold. Effects on affinity of variations in the side chain of the amino acid can be comparable in magnitude to that of the carboxyl group. The effect of sodium ion on the transport system appears to be similar for all compounds tested.
\end{abstract}

The transport of neutral (monoamino-monocarboxylic) amino acids by rabbit ileum has been studied extensively in this laboratory. We have characterized the influx of several amino acids across the brush border and from this information have developed a model of the transport system located in this membrane (1). This model provides a satisfactory explanation of the interaction between $\mathrm{Na}$ and amino acids for influx from mucosal solution into the cell $(1-4)$ and for efflux from the cell toward the mucosal solution $(5,6)$. The model involves sequential binding of the amino acid and $\mathrm{Na}$ to a transport site, and the behavior of the system can be characterized by dissociation constants for the reaction of amino acid with the site and the reaction of $\mathrm{Na}$ with the site. Since this model fits data for the influxes of glycine, alanine, valine, and leucine, we felt that it would be worthwhile to attempt to obtain further information about the nature of the transport site by investigating the behavior of a variety of amino acids and their analogues. There have been previous studies of this type that have led to certain general conclusions regarding the 
amino acid transport system in hamster intestine $(7,8)$. However, most of these studies involved determination of net movement across everted sacs and results obtained with this preparation are sometimes difficult to interpret in terms of specific properties of a transport system located in the brush border. In addition, measurement of net transport across an everted sac against a concentration difference is not sufficiently sensitive to detect movement of poorly transported substances. Some of these difficulties are overcome by measuring directly influx of the amino acids across the brush border. Thus, we have examined the effects of various compounds on phenylalanine influx across the brush border in an effort to characterize the transport system of rabbit ileum more completely.

\section{THEORETICAL CONSIDERATIONS}

All experiments in this study involved investigation of the ability of various substances to inhibit the influx of phenylalanine from the mucosal solution into the cells. As shown below, phenylalanine influx, $J i$, conforms to MichaelisMenten type kinetics so that

$$
J^{i}=\frac{J^{i \max }[\mathrm{Phe}]_{m}}{K_{t}+[\mathrm{Phe}]_{m}}
$$

in which $J^{i \max }$ is maximal influx, $K_{t}$ is the "apparent Michaelis constant," and $[\mathrm{Phe}]_{m}$ is the phenylalanine concentration in the mucosal solution. If another substance which inhibits phenylalanine influx competitively is added to the mucosal solution, we can show easily that

$$
\frac{J_{o}^{i}}{J_{I}^{i}}=1+\frac{K_{t}[I]_{m}}{K_{I}\left(K_{t}+[\mathrm{Phe}]_{m}\right)}
$$

in which $J_{o}^{i}$ is phenylalanine influx in the absence of inhibitor, $J_{I}^{i}$ is influx in the presence of inhibitor, $[I]_{m}$ is the inhibitor concentration, and $K_{I}$ is the "inhibitor constant." If the inhibition is strictly competitive, $K_{I}$ will be equal to the apparent Michaelis constant for the inhibitor, $K_{t(I)}$. According to equation 2, a plot of $J_{o}^{i} / J_{I}^{i}$ against $\left[I_{m} \text { at constant [Phe }\right]_{m}$ should yield a straight line and $K_{I}$ can be evaluated from the slope of the line if $K_{t}$ is known. If the inhibition is strictly noncompetitive, the following relation holds:

$$
\frac{J_{o}^{i}}{J_{I}^{i}}=1+\frac{[I]_{m}}{K_{I}}
$$

Clearly, the effects expressed by equations 2 and 3 can be distinguished by carrying out experiments at different values of $[\mathrm{Phe}]_{m}$. 
According to the model of amino acid transport for rabbit ileum (1), $K_{t}$ is given by

$$
K_{t}=\frac{K_{1} K_{2}}{K_{2}+[\mathrm{Na}]_{m}}
$$

in which $[\mathrm{Na}]_{m}$ is $\mathrm{Na}$ concentration in the mucosal solution; $K_{1}$ is the dissociation constant for the reaction

$$
A+X \hookrightarrow X A
$$

and $K_{2}$ is the dissociation constant for the reaction

$$
X A+\mathrm{Na} \hookrightarrow X A \mathrm{Na}
$$

where $X$ represents the transport site. The details of this model and the assumptions involved in obtaining equation 4 are given by Curran et al. (1). In this study, we are interested in $K_{1}$ which characterizes the interaction between a substance $A$ and the transport site (or amino acid binding site). As indicated below, $K_{2}$ appears to be approximately independent of the nature of $A$. If we assume this to be true for all substances studied, the Michaelis constant, $K_{t(I)}$, for a competing substance would be given by

$$
K_{t(I)}=\frac{K_{1(I)} K_{2}}{K_{2}+[\mathrm{Na}]_{m}}
$$

If we introduce equations 4 and 5 into equation 2 , we obtain

$$
\frac{J_{o}^{i}}{J_{I}^{i}}=1+\frac{K_{1}[I]_{m}}{K_{1(I)}\left(K_{t}+[\mathrm{Phe}]_{m}\right)}
$$

Equation 6 will be used to evaluate the results of the experiments. Justifications for the assumptions involved in obtaining it are discussed below.

\section{METHODS}

All experiments were performed on the ileum of male New Zealand white rabbits. The animals were sacrificed by intravenous injection of sodium pentobarbital, the distal portion of the small intestine was removed, slit open along the mesenteric border, rinsed free of intestinal contents with normal Ringer solution, and mounted in the influx chamber described by Schultz et al. (2). Phenylalanine influx across the mucosal border was determined at $37^{\circ} \mathrm{C}$ as previously described by $60 \mathrm{sec}$ exposure of the mucosal surface only to solution containing ${ }^{14} \mathrm{C}-\mathrm{L}$-phenylalanine and inulin- ${ }^{3} \mathrm{H}$. Influx was calculated from tissue uptake of ${ }^{14} \mathrm{C}$ after correction for the inulin "space."1

${ }^{1}$ In some experiments phenylalanine-3 $\mathrm{H}$ was used to measure influx and polyethylene glycol- ${ }^{14} \mathrm{C}$ was used as the extracellular marker. Results were identical to those obtained with phenylalanine${ }^{14} \mathrm{C}$ and inulin- ${ }^{3} \mathrm{H}$. 
This technique, including appropriate control experiments, has been discussed in detail by Schultz et al. (2), and the present experiments were carried out without modification of the method.

In order to examine a potential inhibitor of phenylalanine influx, the effect of the inhibitor was examined at three concentrations with constant phenylalanine concentration. Since the influx chambers permit eight determinations on tissue from a single animal, each experiment involved duplicated determinations of control influx (no inhibitor) and of influx at three inhibitor concentrations. Duplicate measurements were averaged and the ratio $J_{o}^{i} / J_{I}^{i}$ (equation 2) calculated for each inhibitor concentration. The ratio was then plotted against $[I]$, the slope of the line determined by least squares, and $K_{1(I)}$ calculated (equation 6). At least three experiments were carried out with each inhibitor. In most experiments, phenylalanine concentration was $1 \mathrm{~mm}$ and inhibitor concentrations were selected according to magnitude of the effect and the solubility of the compound. Usually no compensation was made for the increased osmolality due to the inhibitor even though concentrations as high as $60 \mathrm{~mm}$ were occasionally used. Mannitol was used for osmotic compensation in some early experiments but identical results were obtained without compensation. In addition, control fluxes (1 mM phenylalanine) measured in the presence of $60 \mathrm{~mm}$ mannitol averaged $1.4 \pm 0.1 \mu$ moles $/ \mathrm{hr} \mathrm{cm}^{2}$ while flux with no mannitol present averaged $1.3 \pm 0.1 \mu$ moles $/ \mathrm{hr} \mathrm{cm}^{2}$.

The normal Ringer solution contained (mM) $140 \mathrm{NaCl}, 10 \mathrm{KHCO}_{3}, 0.2 \mathrm{KH}_{2} \mathrm{PO}_{4}$, $1.2 \mathrm{~K}_{2} \mathrm{HPO}_{4}, 1.2 \mathrm{MgCl}_{2}$, and $1.2 \mathrm{CaCl}_{2}$ and had a $\mathrm{pH}$ of 7.2 when equilibrated with $95 \% \mathrm{O}_{2}-5 \% \mathrm{CO}_{2}$. Solutions containing inhibitors were adjusted to $\mathrm{pH} 7.2$ with $\mathrm{HCl}$ or $\mathrm{NaOH}$ if necessary and appropriate adjustments of $\mathrm{Na}$ or $\mathrm{Cl}$ concentration were made if significant amounts of $\mathrm{NaOH}$ or $\mathrm{HCl}$ were required. In some experiments, $\mathrm{Na}$ concentration of the solutions was altered by replacing $\mathrm{NaCl}$ with an equivalent amount of choline chloride.

L-Phenylalanine, L-tyrosine, L-tryptophan, L-histidine, and L-methionine were obtained from Sigma Chemical Co. (St. Louis, Mo.), p-amino-DL-phenylalanine, $p$-chloro-DL-phenylalanine, $p$-nitro-DL-phenylalanine, $p$-methyl-DL-phenylalanine, L-phenylalaninol, $\beta$-phenethylamine, $\beta$-phenylpropionic acid, L-phenylalanine amide, and benzamidine from $\mathrm{K} \& \mathrm{~K}$ Laboratories (Plainview, N. Y.), phenyl-Llactic acid, L-phenylalanine methyl ester, and L-mimosine from Aldrich Chemical Co. (Milwaukee, Wis.), $p$-fluoro-DL-phenylalanine, $p$-iodo-DL-phenylalanine, $N$ methyl-L-phenylalanine, and $N$-acetyl-L-phenylalanine from Cyclo Chemical Corp. (Los Angeles, Calif.), and D-phenylalanine and 1-amino-2-phenylethyl phosphonic acid from Calbiochem (Los Angeles, Calif.). ${ }^{14} \mathrm{C}-\mathrm{L}-$ phenylalanine, ${ }^{3} \mathrm{H}-\mathrm{L}-$ phenylalanine, inulin $-{ }^{3} \mathrm{H}$, and polyethylene glycol- ${ }^{14} \mathrm{C}$ were obtained from New England Nuclear Corp. (Boston, Mass.).

\section{RESULTS}

An initial series of experiments was carried out to characterize the kinetics of phenylalanine influx. In each experiment, influx was determined in duplicate at four concentrations of phenylalanine. The $\mathrm{Na}$ concentration in the bathing solution was varied by replacing all or part of the $\mathrm{NaCl}$ by choline chloride. 
At each $\mathrm{Na}$ concentration tested ( $140 \mathrm{~mm}, 20 \mathrm{~mm}$, and $\mathrm{Na}$-free solution) phenylalanine influx conformed to Michaelis-Menten kinetics and values of maximal influx $\left(J^{i_{\max }}\right)$ and the apparent Michaelis constant $\left(K_{t}\right)$ were obtained from plots of concentration divided by influx against concentration. The values obtained are given in Table I, and Fig. 1 shows the reciprocal of $K_{t}$ as a function of $\mathrm{Na}$ concentration in the medium. In accord with the predictions of our model (1), $1 / K_{\imath}$ is a linear function of $[\mathrm{Na}]_{m}$; using the relation given in equation 4 , we calculate that $K_{1}=17.8 \mathrm{~mm}$ and $K_{2}=25 \mathrm{~mm}$. This value of $K_{2}$ is in good agreement with values obtained for glycine, alanine,

T A B L E I

CHARACTERISTICS OF PHENYLALANINE INFLUX

\begin{tabular}{rcc}
\hline [Na] & $\kappa_{t}$ & $J^{\text {imax }}$ \\
\hline$m \boldsymbol{m M}$ & $m$ smoles $/ \mathrm{hr} \mathrm{m}$ \\
140 & $2.7 \pm 0.7$ & $3.5 \pm 0.8$ \\
20 & $10.2 \pm 1.3$ & $3.8 \pm 1.1$ \\
0 & $17.6 \pm 1.2$ & $4.8 \pm 0.5$ \\
\hline
\end{tabular}

Results are based on six experiments at $140 \mathrm{~mm} \mathrm{Na}$, five at $20 \mathrm{~mm}$, and four in $\mathrm{Na}$-free solution.

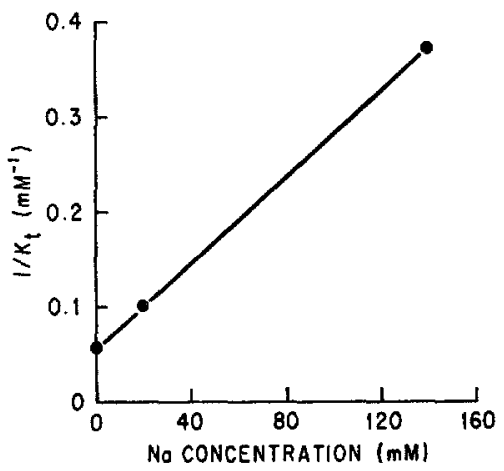

Frgure 1. Relationship between the reciprocal of $K_{t}$ for phenylalanine and $\mathrm{Na}$ concentration in the mucosal solution.

valine, and leucine $(1,4)$. This observation provides some justification for the assumption that $K_{2}$ does not depend on the particular amino acid. This assumption was used to obtain equation 6 from equation 2 and is necessary to obtain $K_{1(I)}$ for the various inhibitors with the methods used here.

Fig. 2 shows the results of inhibition studies with four representative compounds. As indicated by equation 2 or 6 , there is a linear relation between $J_{o}^{i} / J_{I}^{i}$ and concentration of inhibitor. This relation appears to hold regardless of the effectiveness of the inhibitor since $p$-nitrophenylalanine is a very effective inhibitor, phenylpropionic acid is a poor inhibitor, and $p$-aminophenylalanine and benzamidine occupy an intermediate position. Further tests of some of the assumptions involved in obtaining equation 6 will be discussed below. 
The various compounds tested for their ability to inhibit phenylalanine influx can be conveniently divided into four classes involving $(a)$ variations in the side chain of the amino acid, $(b)$ variations of substituents in the benzene ring of phenylalanine, $(c)$ variations of the $\alpha$-amino group, and $(d)$ variations in the carboxyl group. The values of $K_{1}$ obtained for amino acids with different side chains are summarized in Fig. 3. The $K_{1}$ 's for the first five substances have been obtained by direct measurement, glycine by Peterson et al. (4), alanine, valine, and leucine by Curran et al. (1), and phenylalanine in the

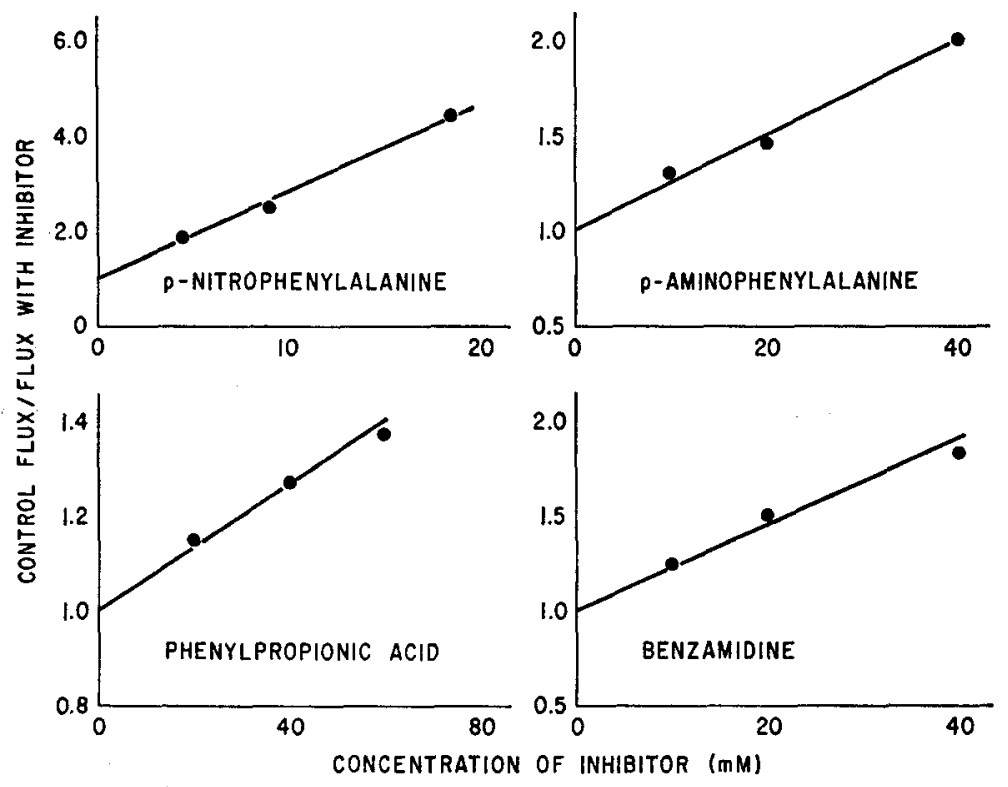

Figure 2. Inhibition of phenylalanine influx plotted as indicated by equation 6 . Each figure shows the results of an experiment on tissue from a single animal. The points are means of duplicate flux determinations. Phenylalanine concentration was $1 \mathrm{~mm}$.

present study. The $K_{1}$ given for histidine was obtained by inhibition, but Chez, Schultz, and Curran (unpublished observations) have obtained a value of $70 \mathrm{~mm}$ by direct measurement of histidine influx. The agreement between these two determinations indicates that the present method provides reasonable estimates of $K_{1}$. In addition, we have previously shown (1) that values for $K_{1}$ for valine and leucine estimated from their abilities to inhibit alanine influx agree well with estimates based on direct influx measurements. The first six amino acids in Fig. 3 show a progressive decrease in $K_{1}$ with an increase in length of the side chain and as shown in Fig. 4, there is a linear relation between affinity $\left(1 / K_{1}\right)$ for the transport site and molecular weight for these amino acids.

Since the results with tyrosine and mimosine suggested that introduction of 
substituents having polar character into the ring of phenylalanine decreased affinity (increased $K_{1}$ ), we proceeded to examine the effects of a variety of such substituents. The results, given in Table II, indicate a considerable variation ranging from a fourfold increase in binding for the $p$-nitro compound to a fivefold decrease for $p$-aminophenylalanine. ${ }^{2}$ Evaluation of the results of these

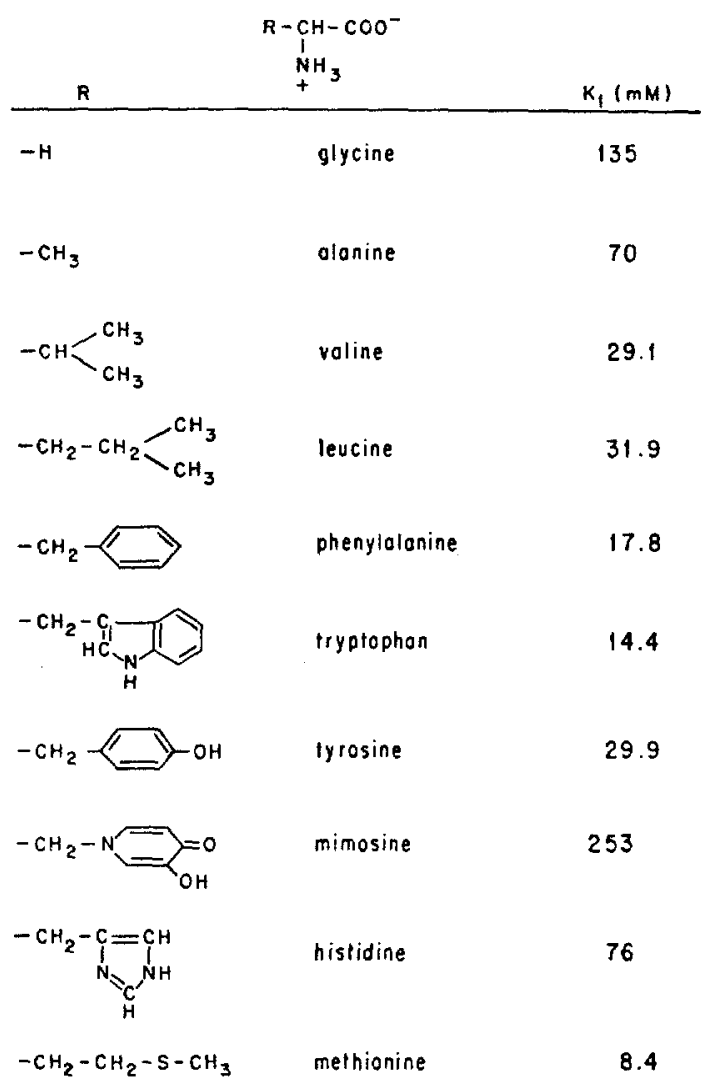

Figure 3. Effect of the side chain of amino acids on interaction with the transport site.

studies was complicated by the fact that some of the substances were available only in the DL form. Since the transport system in intestine is known to discriminate to some degree at least between the $\mathrm{D}$ and $\mathrm{L}$ isomers of neutral amino acids $(9,10)$, information on the degree of discrimination under our conditions is necessary in order to estimate $K_{1}$. Consequently, we carried out four experiments testing the effect of $D$-phenylalanine on the influx of L-phenylalanine. The $\mathrm{D}$ compound did inhibit but poorly and a $K_{1}$ of $200 \mathrm{~mm}$ was obtained. Since these results indicate that the $\mathrm{D}$ isomer has less than one-tenth the affinity

2 We have not given detailed statistical analysis of these and other results because they do not affect the arguments. For good inhibitors of phenylalanine influx, the SEM of the $K_{1}$ was usually $10 \%$ or less. For poorer inhibitors $\left(K_{1}>100 \mathrm{mM}\right)$, the SEM was usually in the range of 10 to $20 \%$. 
of the $\mathrm{L}$ isomer for the transport system, we have assumed that the effect of the $\mathrm{D}$ form can be neglected in studies with DL mixtures. For those compounds, the effective concentration (of the $\mathrm{L}$ form) has been taken as one-half of the total concentration in computing $K_{1(r)}$.

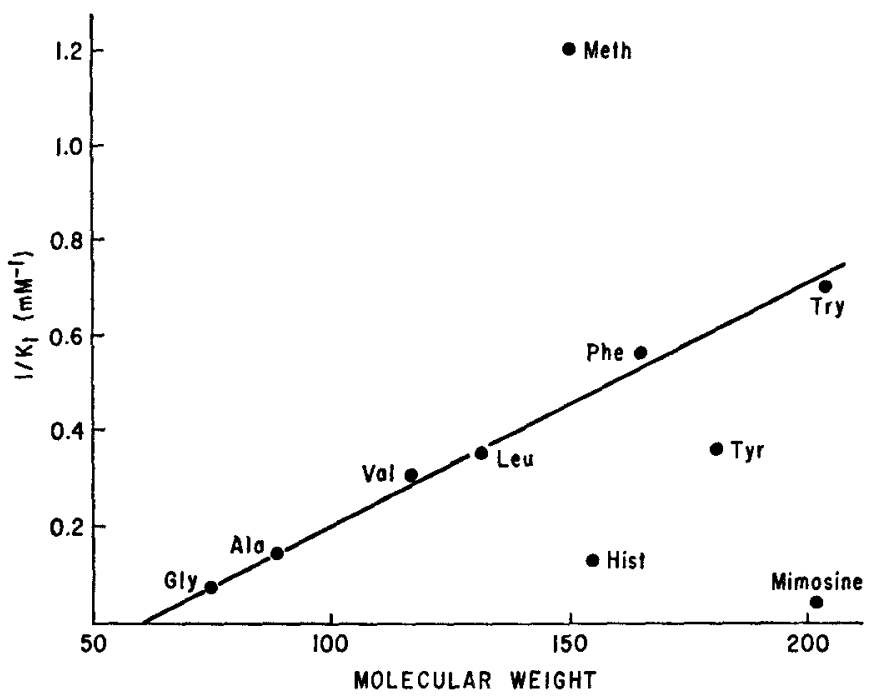

FIgure 4. Relationship between molecular weight of an amino acid and its affinity for the transport system $\left(1 / K_{1}\right)$.

T A B L E I I

EFFECT OF RING SUBSTITUENTS

\begin{tabular}{lc}
\hline Subutituent* & $R_{1}$ \\
\hline & $m \boldsymbol{k}$ \\
$-\mathrm{NO}_{2}$ & 4.0 \\
$-\mathrm{I}$ & 7.0 \\
$-\mathrm{CI}$ & 4.3 \\
$-\mathrm{F}$ & 15.8 \\
$-\mathrm{H}$ & 17.8 \\
$-\mathrm{CH}_{3}$ & 25.0 \\
$-\mathrm{OH}$ & 29.9 \\
$-\mathrm{NH}_{2}$ & 97 \\
\hline
\end{tabular}

* All substituents studied were in the para-position.

Results obtained with substances involving alteration of the carboxyl and $\alpha$-amino groups of phenylalanine are summarized in Tables III and IV. A few qualifying comments regarding some of these results are necessary. $N$ Acetyl phenylalanine was an inhibitor sufficiently poor that the usual technique could not be used so it was studied using a single concentration ( $60 \mathrm{~mm}$ ). In each experiment, there were four control measurements and four test 
measurements with inhibitor present. There were consistent but small effects and the value of $K_{1(I)}$ obtained is not very accurate. A similar technique was used for $N$-methyl phenylalanine at a concentration of $40 \mathrm{~mm}$. As indicated by the results in Table III, the methyl ester and the amide of phenylalanine appear to be rather effective inhibitors of phenylalanine influx suggesting that an ionized carboxyl group may not be essential for interaction with the transport site. However, Spencer et al. (8) have shown that the amide of tyrosine is

T A B L E I I I

EFFEGT OF ALTERATIONS IN THE CARBOXYL GROUP $\left(\mathrm{C}_{6} \mathrm{H}_{5}\right) \mathrm{CH}_{2} \mathrm{CHN}^{+} \mathrm{H}_{3} \cdot \mathrm{R}$

\begin{tabular}{|c|c|c|}
\hline $\mathbf{R}$ & & $\boldsymbol{K}_{1}$ \\
\hline & & $m \boldsymbol{s}$ \\
\hline$-\mathrm{COO}^{-}$ & Phenylalanine & 17.8 \\
\hline$-\mathrm{COOCH}_{3}$ & Phenylalanine methyl ester & 39.0 \\
\hline$-\mathrm{CONH}_{2}$ & Phenylalanine amide & 33.6 \\
\hline$-\mathrm{H}$ & $\beta$-Phenethylamine & 229 \\
\hline$-\mathrm{CH}_{2} \mathrm{OH}$ & Phenylalaninol & 229 \\
\hline$=\mathrm{NH}$ & Benzamidine* & 213 \\
\hline$-\mathrm{PO}_{3}=$ & 1-Amino-2-phenylethyl phosphonic acid & 385 \\
\hline
\end{tabular}

* The complete structure of benzamidine is $\left(\mathrm{C}_{6} \mathrm{H}_{5}\right) \mathrm{CHN}^{+} \mathrm{H}_{3}: \mathrm{NH}$.

TA BLE IV

EFFECT OF ALTERATIONS IN THE AMINO GROUP $\left(\mathrm{C}_{6} \mathrm{H}_{8}\right) \mathrm{CH}_{2} \mathrm{CHR} \cdot \mathrm{COO}^{-}$

\begin{tabular}{|c|c|c|}
\hline $\mathbf{R}$ & & $K_{1}$ \\
\hline & & $m M$ \\
\hline$-\mathrm{NH}_{3}{ }^{+}$ & Phenylalanine & 17.8 \\
\hline$-\mathbf{H}$ & Phenylpropionic acid & 870 \\
\hline$-\mathrm{OH}$ & Phenyllactic acid & 1240 \\
\hline$-\mathrm{NH}_{2}+\mathrm{CH}_{3}$ & $N$-methyl phenylalanine & 780 \\
\hline$-\mathrm{NHCOCH}_{3}$ & $N$-acetyl phenylalanine & $\sim 2500$ \\
\hline
\end{tabular}

split fairly rapidly by hamster intestine. Thus, the apparent inhibition caused by the amide may well be due to the presence of extra phenylalanine as a result of enzyme activity rather than to the amide itself. On the other hand, Lin et al. (7) found that histidine methyl ester was not split appreciably by hamster intestine.

The values of $K_{1}$ presented in these tables were calculated using two assumptions: $(a)$ that the substances were competitive inhibitors of phenylalanine transport and $(b)$ that $K_{2}$ (the dissociation constant for the combination $\mathrm{Na}$ with the binary complex) was the same for all substances tested. Some experiments were carried out to test these assumptions. If a substance is a competitive 
inhibitor, the same value of $K_{1(I)}$ should be obtained in experiments carried out at different concentrations of phenylalanine. Table $\mathrm{V}$ shows that this result was obtained with $p$-nitrophenylalanine, benzamidine, and phenylalanine methyl ester. ${ }^{3}$ If $K_{2}$ is the same for an inhibitor and for phenylalanine, the calculated $K_{1(I)}$ should be independent of the $\mathrm{Na}$ concentration in the bathing solution. Table $\mathrm{V}$ also shows that this is true for $p$-chlorophenylalanine, benzamidine, and phenylalanine methyl ester. In addition, we can calculate $K_{t(I)}$ for the $p$-chloro compound from equation 2 and examine its behavior as a function of $\mathrm{Na}$ concentration. As shown in Fig. $5,1 / K_{t}$ is a linear function of $[\mathrm{Na}]_{m}$ and from the slope and intercept of the line and equation 4 we find that $K_{2}=25 \mathrm{~mm}$ for $p$-chlorophenylalanine, exactly the same value

T A B L E V

EFFECTS OF Na AND PHENYLALANINE CONCENTRATIONS ON THE $\mathrm{K}_{1}$ OF INHIBITORS

\begin{tabular}{lccc}
\hline Inhibitor & [Na] & [Phe] & $K_{1}$ \\
\hline \multirow{2}{*}{$p$-Nitrophenylalanine } & $m$ m & $m M$ & $m M$ \\
p-Chlorophenylalanine & 140 & 1 & 3.9 \\
& 140 & 10 & 4.1 \\
Benzamidine & 140 & 1 & 8.1 \\
& 70 & 1 & 9.1 \\
Phenylalanine methyl ester & 20 & 1 & 6.8 \\
& 140 & 1 & 213 \\
& 140 & 5 & 238 \\
& 20 & 1 & 197 \\
& 140 & 1 & 39 \\
& 140 & 1 & 43 \\
\hline
\end{tabular}

obtained for phenylalanine itself. A similar analysis based on points at only two Na concentrations gives $K_{2}=26 \mathrm{~mm}$ for benzamidine and $K_{2}=28 \mathrm{~mm}$ for phenylalanine methyl ester. The results of these experiments offer reasonable justification for the assumptions used to evaluate $K_{1(I)}$.

In order to test whether some of these compounds had relatively nonspecific effects on transport across the mucosal border, the influence of phenylpropionic acid, benzamidine, phenylalaninol, and phenethylamine on 3-O-methyl glucose (3-MG) influx was examined. The first three substances at concentrations of $40 \mathrm{~mm}$ had no significant effect; phenylpropionic acid caused a $4 \%$ increase in 3-MG influx while benzamidine and phenylalaninol caused a 5\%

${ }^{3}$ No attempt was made to show that the inhibition caused by compounds lacking the $\alpha$-amino group is competitive. The minimal inhibition observed at $1 \mathrm{~mm}$ phenylalanine suggests that experiments at higher concentrations would yield equivocal results. Consequently, the estimated $K_{1}$ 's for these compounds should be considered minimal values. The results presented clearly indicate the major role played by the $\alpha$-amino group. 
decrease. However, phenethylamine $(40 \mathrm{~mm}$ ) caused a $40 \%$ decrease in 3MG influx suggesting a nonspecific effect. The inhibition seems noncompetitive because approximately the same per cent decrease in influx was noted at two concentrations of 3-MG. We, therefore, carried out two additional experiments to test the effect of this compound on phenylalanine influx. The effect of $40 \mathrm{~mm}$ phenethylamine was examined at 1 and $5 \mathrm{~mm}$ phenylalanine using tissue from the same animal and in one of these experiments, phenylalaninol was also tested. The mean calculated $K_{1}$ 's for phenethylamine were $270 \mathrm{~mm}$ at $1 \mathrm{~mm}$ phenylalanine and $278 \mathrm{~mm}$ at $5 \mathrm{~mm}$ phenyl-

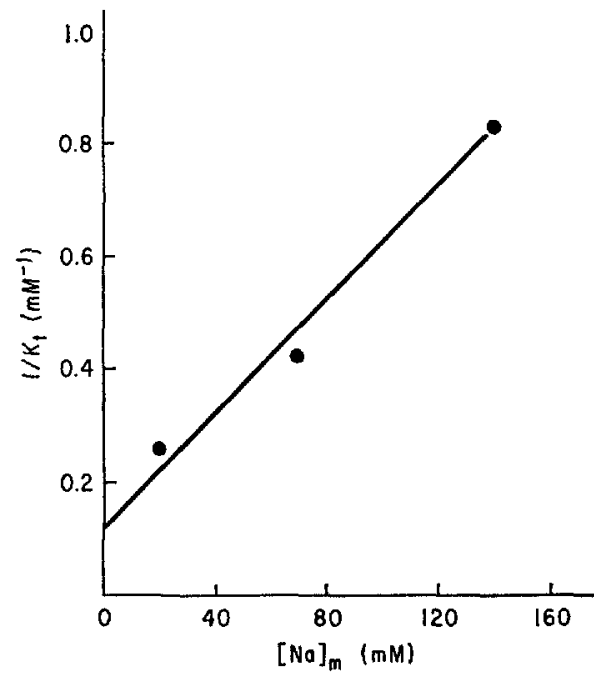

Figure 5. Relation between the reciprocal of $K_{t}$ for $p$-chlorophenylalanine and $\mathrm{Na}$ concentration in the mucosal solution.

alanine while the $K_{1}$ for phenylalaninol was $260 \mathrm{~mm}$. These results indicate that phenethylamine is a competitive inhibitor of phenylalanine influx and are consistent with those given in Tables III and V. The nature of the effect of phenethylamine on 3-MG influx remains unclear, but it does not appear to be involved in the effect on phenylalanine. However, in view of these observations, the $K_{1}$ for phenethylamine should probably be considered a minimum value.

\section{DISGUSSION}

The results of these studies indicate that the $\alpha$-amino group, the carboxyl group, and the side chain all influence significantly the binding of an amino acid to its transport site in rabbit ileum. These points have been demonstrated, at least in a qualitative manner, in previous studies $(7,8,11)$. These studies led to the conclusion that the $\alpha$-amino and carboxyl groups are both required for transport by intestine. For example, Lin et al. (7) found no active transport of histidine methyl ester, histidinol, or phenylpyruvic acid by hamster in- 
testine and Spencer et al. (8) were unable to demonstrate active transport of a variety of compounds involving replacements or alterations in the carboxyl group. However, those studies were based mainly on the ability of the intestine to transport the test substances against concentration differences and with that technique, quantitative evaluation of the effects of changes in the molecule is difficult. In particular, it is difficult to distinguish between a molecule that has no affinity for the transport system and one that has a relatively low affinity. In the present study we have concentrated more closely on the transport system in the brush border by investigating only unidirectional influx across that border, and our results indicate that compounds analogous to those used by Lin et al. and Spencer et al. have small but detectable abilities to inhibit influx of phenylalanine.

The quantitative evaluation of our results is based on a specific kinetic model of the transport system. Within the context of the model, we are able to evaluate the binding constant $\left(1 / K_{1}\right)$ of a variety of substances for the amino acid site in the transport system. ${ }^{4}$ Although considerable evidence has now been accumulated that is entirely consistent with this model $(1,4-6)$, other models, as yet undiscovered, may be equally good. However, even if the model turns out to be incorrect, the general patterns observed in this study should provide useful information regarding some properties of the transport system. In this regard, we should note that the values of $K_{1}$ given in the tables and figures can be converted to apparent Michaelis constants, $K_{t}$ 's, by dividing them by 6.6. (For the data in Table $V$, the conversion factor is 3.8 at $70 \mathrm{~mm}$ $\mathrm{Na}$ and 1.8 at $20 \mathrm{~mm} \mathrm{Na}$.) These $K_{\imath}$ 's represent rather general properties of the transport system that would have to be explained by any model. In discussing the results, we shall make use of our present working model and use the $K_{1}$ 's with the assumption that their reciprocals represent binding constants for substrates to the transport site.

\section{Effect of the $\alpha$-Amino Group}

The results in Table IV indicate that the $-\mathrm{NH}_{3}^{+}$group plays an important role in the binding of the amino acid to the site. Replacement of this group by $-\mathrm{H}$ or $-\mathrm{OH}$ reduces affinity by a factor of approximately 50 . Addition of other groups to the amino group also reduces affinity drastically and the affinity of $N$-acetyl phenylalanine is so low that it is barely detectable by the present method. However, even a relatively small group such as $-\mathrm{CH}_{3}$ reduces affinity markedly. Since the amino group retains a positive charge in $N$-methyl phenylalanine, it seems likely that the primary effects of substitu-

${ }^{4}$ We should note that there is no model of a transport system involving $\mathrm{Na}$ and amino acids in which the apparent Michaelis constant, $K_{t}$, can be identified with the affinity of the transport site for the amino acid. Thus a specific model with a known relation between $K_{t}$ and affinity of the site is needed in order to attempt interpretation in molecular terms. 
tions on the nitrogen are steric in nature. Thus, the site involved in the interaction between the $-\mathrm{NH}_{3}^{+}$group and the transport system appears to have little tolerance for groups larger than hydrogen. In fact, the data in Table IV indicate that the decrease in affinity resulting from the introduction of a methyl group into the $-\mathrm{NH}_{3}^{+}$group is nearly equivalent to that caused by removal of the amino group.

\section{Effect of the Carboxyl Group}

As shown in Table III, removal of the - $\mathrm{COO}^{-}$group from phenylalanine causes approximately a 12-fold decrease in affinity for the transport site. Within the limits investigated, the effect is independent of the group used to replace the - $\mathrm{COO}^{-}$since phenylalaninol, phenethylamine, and benzamidine have essentially the same affinity. This result is somewhat at variance with previous reports $(7,8,11)$ that the carboxyl is essential for transport since substances without this group appear to have a definite affinity for the transport site and might be expected to undergo transport although at a rather low rate when present at concentrations in the millimolar range. As indicated by the data in Table $\mathrm{V}$, benzamidine is a competitive inhibitor of phenylalanine transport and has a $K_{2}$ identical with that of phenylalanine. It thus appears to be an appropriate substrate for the transport system. These results also seem somewhat at variance with recent reports regarding the behavior in other tissues of compounds lacking the carboxyl group. Kittams and Vidaver (12) found that $\beta$-phenethylamine and related compounds inhibit glycine transport in pigeon erythrocytes but the inhibition is noncompetitive. Christensen and Liang (13) have observed mediated transport of benzylamine into Ehrlich ascites tumor cells but the process involved appears to be different than those mediating amino acid transport. Additional studies on the handling of this type of compound by the intestine are clearly necessary.

The question of whether the carboxyl group requires a negative charge for maximal affinity is uncertain. The results in Table III indicate that both the methyl ester and the amide of phenylalanine have substantial affinity for the transport system. However, as discussed above there is evidence (8) that the amide is split by the intestine and the observed effect may be due to the free phenylalanine that is released. Available evidence (7) suggests that the methyl ester is not split and the fact that it is a good inhibitor suggests that the essential feature of the carboxyl group for binding might be the $-\mathrm{C}=\mathrm{O}$ group. The results obtained with the phosphonic acid analogue of phenylalanine indicate that negative charge per se is not sufficient to insure high affinity for the site; this compound actually has a lower affinity than those having an uncharged group substituted for the carboxyl group. There is an additional possible complication with the experiments on the methyl 
ester, the amide, and probably phenylalaninol. The $\mathrm{pK}_{\mathrm{a}}$ of the amino group is changed to 7.0 in the ester and 7.3 in the amide (14) (the $\mathrm{pK}_{\mathrm{a}}$ of the amino group in phenylalanine is 9.2). Thus at the $\mathrm{pH}$ of the experiments (7.2) an appreciable fraction of the ester and amide molecules will have an uncharged $\alpha$-amino group and this may affect the affinity. This point clearly requires further study and it may also provide a means of examining the charge requirement on the amino group because in these compounds the charge can be varied over a considerable range by $\mathrm{pH}$ changes around a value of 7.0.

\section{Effect of the Side Chain}

As discussed by Peterson et al. (4) and by Schultz and Curran (15), evidence from direct influx measurements for five neutral amino acids (glycine, alanine, valine, leucine, and phenylalanine) indicates that the affinity of the amino acid for the transport site $\left(1 / K_{1}\right)$ increases progressively with the number of carbon atoms in the side chain. They have pointed out that this relationship suggests that the amino acid site possesses a hydrophobic region with which the side chain of the amino acid associates. The present results appear to be consistent with this concept. As shown in Fig. 4, tryptophan, which has a nonpolar side chain, follows quite well the relation between $1 / K_{1}$ and molecular weight defined by five amino acids studied by direct influx measurement. However, amino acids having some polar character in the side chain such as tyrosine, histidine, and mimosine have appreciably lower affinities for the transport site and do not conform to the relation defined by amino acids containing exclusively (or mainly) methyl or methylene groups in the side chain. Methionine, with a sulfur in the side chain, also does not conform to this relation but it has a much higher affinity than expected. The reason for this effect is unknown at present but Daniels et al. (16) have recently reported that the effectiveness of other amino acids in inhibiting net transmural transport of methionine by rat intestine increases with the length of the side chain. A decrease in $K_{t}$ for net transmural transport with increase in length of the side chain has been observed for rat intestine $(17,18)$. However, as pointed out by Matthews and Laster (18) transmural transport is a sufficiently complex phenomenon that a precise meaning cannot be easily applied to $K_{t}$ values obtained for the process. In the ascites cell, amino acids with large nonpolar side chains appear to be transported by a separate system (19).

\section{Effect of Ring Substituents}

The results of studies with analogues of phenylalanine involving substitutions in the benzene ring appear to depend on the action of the substituent on the electron density in the ring. Substances with electron-withdrawing groups such as $-\mathrm{NO}_{2}$ and $-\mathrm{Cl}$ have a higher affinity than phenylalanine itself 
while electron-releasing groups such as $-\mathrm{OH}$ and $-\mathrm{NH}_{2}$ reduce affinity relative to phenylalanine. (Although we have not found any direct information on the $\mathrm{pK}_{\mathrm{a}}$ of the amino group in $p$-aminophenylalanine, it should be uncharged at $\mathrm{pH} 7.2$; for example, the $\mathrm{pK}_{\mathrm{a}}$ 's of the ring $-\mathrm{NH}_{2}$ groups in 2-aminobenzoic acid, analine, and 3-propyl analine are 4.9, 4.6, and 4.7, respectively (14).) The behavior of the ring-substituted compounds appears to follow fairly closely the predictions of the Hammett sigma function. This function provides a measure of the electron-withdrawing or electron-releasing capacity of the substituent and is given by the relation

$$
\log \left(K / K_{0}\right)=\rho \sigma
$$

in which $K_{o}$ is the equilibrium constant or rate constant for the unsubstituted compound and $K$ is the constant for the substituted compound. The quantity $\rho$ is referred to as the rate constant and $\sigma$ is a measure of the effect of substituents on the ionization constant of substituted benzoic acids. It is given by

$$
\sigma=\log \left(k / k_{o}\right)
$$

in which $k_{o}$ is the dissociation constant for benzoic acid and $k$ is the value for the substituted compound. As shown in Fig. 6 the results of the present

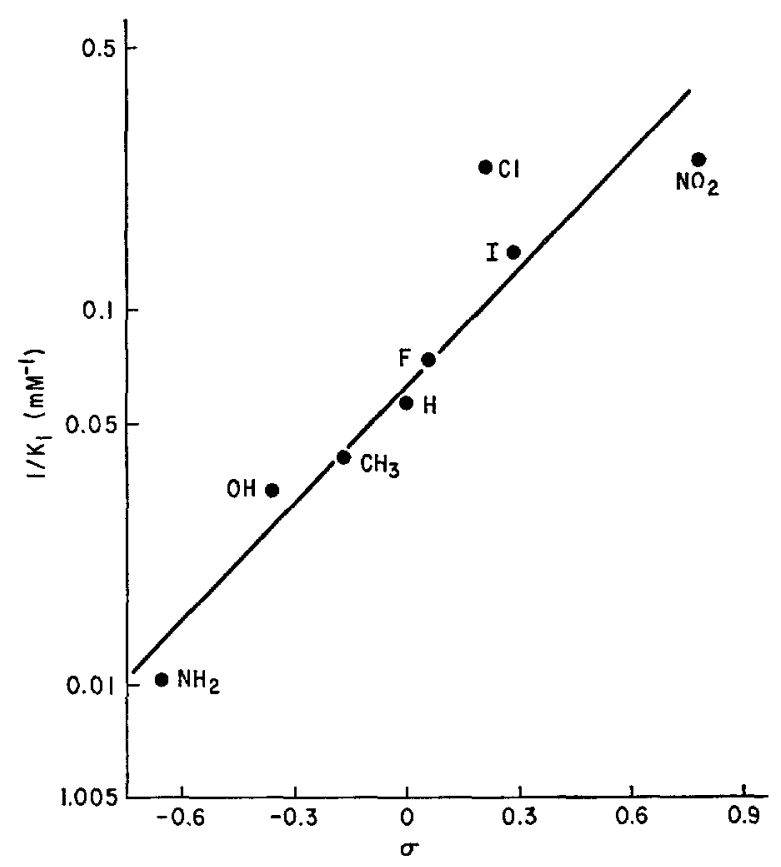

Figure 6. Effect of para-substitution on affinity of phenylalanine for the transport site. The Hammett function $\sigma$ is defined in the text. 
study conform reasonably well to the predictions of equation 7 since there is nearly a linear relation between $\log \left(1 / K_{1}\right)$ and $\sigma$. (Sigma values were taken from the compilation of Jaffé (20).)

It is of interest to note that Fonda and Anderson (21) have observed a rather similar relationship between affinity and ring-substituted competitive inhibitors of $\mathbf{D}$-amino acid oxidase. They suggest that this observation may indicate the involvement of a hydrophobic binding site in the enzyme and that the most likely interaction involved would be between the ring of the substrate and the ring of an aromatic amino acid in the enzyme. Increase in length of the side chain also increases affinity of substrates and inhibitors of $\mathrm{D}$-amino acid oxidase $(21,22)$ but the effect is limited to about 4 carbon atoms indicating that the hydrophobic region has a rather limited capacity. The present observations are quite similar. The data shown in Fig. 4 suggest the involvement of a hydrophobic portion of the transport site in the binding of the amino acid. Since withdrawal of electrons from the ring of phenylalanine appears to enhance binding, it seems reasonable to suggest that the hydrophobic interaction involves an association between this ring and a similar structure in the hydrophobic region of the site. This seems the most likely explanation at present for the results shown in Fig. 6 since there is independent evidence suggesting that the region of the transport site with which the side chain interacts is a hydrophobic one. ${ }^{5}$

\section{Quantitative Considerations}

Since we have interpreted $K_{1}$ as an equilibrium constant for the reaction between an amino acid and its transport site, we can use the present data to estimate the contribution of various parts of the amino acid molecule to the over-all binding energy. The standard free energy change $\left(\Delta G^{\circ}\right)$ for a reaction is given by

$$
\Delta G^{o}=-R T \ln K
$$

in which $K$ is the equilibrium constant for the reaction and $R$ and $T$ have their usual significance. For the present case, the change in standard free energy resulting from a change in the molecule would be given by

$$
\Delta\left(\Delta G^{o}\right)=-R T \ln \left(K_{1(\mathrm{ref})} / K_{1}\right)
$$

in which $K_{1(\mathrm{ref})}$ is $K_{1}$ for a reference compound and $K_{1}$ is the value for the test compound. The results of such calculations are given in Table VI and provide an indication of the contributions of the amino and carboxyl groups,

\footnotetext{
5 The changes in affinity with para-substitution cannot be ascribed to changes in dissociation constants of the amino or carboxyl groups because the pK's of several $p$-substituted phenylalanines are nearly identical with those of the parent compound.
} 
the side chain, and ring substituents to the over-all binding energy for an amino acid. The largest contribution appears to come from the amino group since addition of $-\mathrm{NH}_{3}^{+}$to phenylpropionic acid increases the binding energy by $2300 \mathrm{cal} / \mathrm{mole}$. The carboxyl group and the side chain (phenylalanine compared to glycine) have similar contributions to binding energy but are only about one-half as effective as the $-\mathrm{NH}_{3}^{+}$group. As indicated by Fig. 4 the contribution of the side chain depends on its length or number of methyl groups. From the slope of the line in Fig. 4 and equation 8 , we can calculate that the contribution of a single methyl group in the side chain to binding energy is approximately $200 \mathrm{cal} / \mathrm{mole}$. This value is in reasonable agreement with that expected for hydrophobic interactions (23). As indicated in Table

T A B L E VI

EFFECT OF SUBSTITUENTS ON FREE ENERGY

\begin{tabular}{cllc}
\hline Substituent & \multicolumn{1}{c}{ Reference } & \multicolumn{1}{c}{ Test } & $\Delta\left(\Delta G^{o}\right)$ \\
\hline & & & cal/mole \\
$-\mathrm{NH}_{3}{ }^{+}$ & Phenylpropionic acid & Phenylalanine & -2300 \\
$-\mathrm{COO}^{-}$ & Phenethylamine & Phenylalanine & -1500 \\
Side chain & Glycine & Phenylalanine & -1200 \\
$p-\mathrm{NO}_{2}$ & Phenylalanine & $p$-Nitrophenylalanine & -900 \\
$p-\mathrm{NH}_{2}$ & Phenylalanine & $p$-Aminophenylalanine & 1100 \\
\hline$\Delta\left(\Delta G^{o}\right)=-R T \ln \left[\mathrm{K}_{1(\text { ref })} / \mathrm{K}_{1(\text { teat })}\right]$. & &
\end{tabular}

VI, substituents in the benzene ring of phenylalanine can alter the binding energy by the order of $1000 \mathrm{cal} / \mathrm{mole}$. These calculations suggest that all parts of the amino acid molecule make significant contributions to the interaction with the transport site; the $-\mathrm{NH}_{3}^{+}$group appears to be the most important but its contribution is by no means dominant. Arrangement at the $\alpha$-carbon atom is clearly important since the binding energy of $\mathrm{D}$-phenylalanine is lower by about $1500 \mathrm{cal} / \mathrm{mole}$ than that of the $\mathrm{L}$ isomer. In other words, the "wrong" configuration at the $\alpha$-carbon is approximately equivalent to complete removal of the - $\mathrm{COO}^{-}$group. This seems to be a reasonable result since if the amino acid is in the wrong configuration, either the amino or carboxyl group (or perhaps the side chain) should be unable to interact with its appropriate receptor site.

These studies lead to a picture of the amino acid binding site in the transport system that is qualitatively similar to that suggested by Wilson (24) but they give additional quantitative insight into various aspects of the system. They provide considerable support for the concept of a hydrophobic interaction between the side chain of the amino acid and the transport site and indicate that neither the $-\mathrm{NH}_{3}^{+}$group nor the $-\mathrm{COO}^{-}$group is absolutely essential for interaction of a substance with the transport site. Further studies 
of this type could lead to a better definition of properties of the transport site and perhaps to a better understanding of the nature of the interaction with $\mathrm{Na}$. Clearly, it will now be essential to examine directly the transport (influx) of at least some of the compounds studied here. The model (1) indicates that any substance that combines with the site should be transported into the mucosal cells. This point should, however, be tested directly. Finally, we should note again that the results have been interpreted in terms of a specific model of the transport system. Even if this model is not entirely correct, the data obtained provide additional information on the properties of the system that must be considered in any model. However, the present model appears to provide a reasonable starting point for consideration of the results and the interpretations in terms of the model seem sensible and consistent.

This work was supported by a United States Public Health Service Research Grant (AM-12028) from the National Institute of Arthritis and Metabolic Diseases.

Dr. Hajjar was on leave of absence from the Department of Physiology, American University of Beirut, Lebanon.

We are indebted to Miss Anne S. Lamont for valuable technical assistance.

Received for publication 22 May 1970.

\section{RE FERE N CES}

1. Gurran, P. F., S. G. Schultz, R. A. Chez, and R. E. Fuisz. 1967. Kinetic relations of the Na-amino acid interaction at the mucosal border of intestine. J. Gen. Physiol. 50:1261.

2. Schultz, S. G., P. F. Curran, R. E. Fuisz, and R. A. Ghez. 1967. Alanine and sodium fluxes across the mucosal border of rabbit ileum. J. Gen. Physiol. 50:1241.

3. Alvarez, O., A. M. Goldner, and P. F. Curran. 1969. Alanine transport in rabbit jejunum. Amer. J. Physiol. 217:946.

4. Peterson, S. C., A. M. Goldner, and P. F. Gurran. 1970. Glycine transport in rabbit ileum. Amer. J. Physiol. 219:1027.

5. Hajjar, J. J., A. S. Lamont, and P. F. Curran. 1970. The sodium-alanine interaction in rabbit ileum: effect of sodium on alanine fluxes. J. Gen. Physiol. 55:277.

6. Gurran, P. F., J. J. HajJar, and I. M. Glynn. 1970. The sodium-alanine interaction in rabbit ileum: effect of alanine on sodium fluxes. J. Gen. Physiol. 55:297.

7. Lin, E. C. C., H. Hagrhara, and T. H. Wilson. 1962. Specificity of the transport system for neutral amino acids in hamster intestine. Amer. J. Physiol. 202:919.

8. Spencer, R. P., K. R. Brody, and F. A. Vishno. 1966. Role of the carboxyl group in intestinal amino acid transport. Biochim. Biophys. Acta. 117:410.

9. Jervis, E. L., and D. H. Smyth. 1960. The active transfer of D-methionine by the rat intestine in vitro. J. Physiol. (London). 151:51.

10. Field, M., S. G. Schultz, and P. F. Curran. 1967. Alanine transport across isolated rabbit ileum. Biochim. Biophys. Acta. 135:236.

11. Spencer, R. P., J. Weinstein, A. Sussman, T. M. Bow, and M. A. Markulis. 1962. Effect of structural analogues on intestinal accumulation of glycine. Amer. J. Physiol. 203:634.

12. Kittams, D. W., and G. A. Vidaver. 1969. Inhibition by $\beta$-phenylethylamine and similar compounds of glycine transport by pigeon red cells. Biochim. Biophys. Acta. 173:540.

13. Ghristensen, H. N., and M. Liang. 1969. Modes of uptake of benzylamine by the Ehrlich cell. J. Biol. Chem. 241:5552.

14. Perrin, D. D. 1965. Dissociation Constants of Organic Bases in Aqueous Solution. Butterworth \& Co. (Publishers) Ltd., London. 
15. Schultz, S. G., and P. F. Curran. 1970. Coupled transport of sodium and organic solutes. Physiol. Rev. 50:637.

16. Daniels, V. G., A. G. Dawson, H. Newey, and D. H. Smyth. 1969. Effect of carbon chain length and amino group position on neutral amino acid transport systems in rat small intestine. Biochim. Biophys. Acta. 173:575.

17. Nathans, D., D. G. TApley, and J. R. Ross. 1960. Intestinal transport of amino acids studied in vitro with L-[181I] monoiodotyrosine. Biochim. Biophys. Acta. 41:271.

18. Matthews, D. M., and L. Laster. 1965. Kinetics of intestinal active transport of five neutral amino acids. Amer. J. Physiol. 208:593.

19. Oxender, D. L., and H. N. Christensen. 1963. Distinct mediating systems for the transport of neutral amino acids by the Ehrlich cell. J. Biol. Chem. 238:3686.

20. JAFFE, H. H. 1953. A reexamination of the Hammett equation. Chem. Rev. 54:191.

21. FondA, M. L., and B. M. Anderson. 1968. D-amino acid oxidase. II. Studies of substratecompetitive inhibitors. J. Biol. Chem. 243:1931.

22. Dixon, M., and K. KLeppe. 1965. D-amino acid oxidase. II. Specificity, competitive inhibition and reaction sequence. Biochim. Biophys. Acta. 96:368.

23. Nemethy, G., and H. A. Saheraga. 1962. The structure of water and hydrophobic bonding in proteins. III. The thermodynamic properties of hydrophobic bonds in proteins. J. Phys. Chem. 66:1773.

24. Wilson, T. H. 1962. Intestinal Absorption. W. B. Saunders Co., Philadelphia. 